\title{
The Posterior Transpetrosal Approach in a Case of Large Retrochiasmatic Craniopharyngioma: Operative Video and Technical Nuances
}

\author{
Moujahed Labidi ${ }^{1,2}$ Kentaro Watanabe ${ }^{1}$ Marie-Pier Loit ${ }^{1}$ Shunya Hanakita ${ }^{1}$ Sébastien Froelich ${ }^{1,3}$ \\ ${ }^{1}$ Department of Neurosurgery, Hôpital Lariboisière, Paris, France \\ ${ }^{2}$ Division of Neurosurgery, Centre Hospitalier de l'Université de \\ Address for correspondence Moujahed Labidi, MD, FRCSC, \\ Department of Neurosurgery, Hôpital Lariboisière, Assistance \\ Publique-Hôpitaux de Paris 2, Rue Ambroise Paré, Paris, France \\ Montréal, Montréal, Québec, Canada \\ 3 Paris VII-Diderot University, Paris, France \\ (e-mail: Moujahed.I@gmail.com).
}

J Neurol Surg B 2018;79(suppl S2):S205-S207.

\begin{abstract}
Keywords

- craniopharyngioma

- transtubercular approach

- petrosal approach

- endoscopic assistance

- skull base

Objectives To discuss the use of the posterior petrosal approach for the resection of a retrochiasmatic craniopharyngioma.

Design Operative video.

Results In this case video, the authors discuss the surgical management of a large craniopharyngioma, presenting with mass effect on the third ventricle and optic apparatus. A first surgical stage, through an endoscopic endonasal transtubercular approach, allowed satisfactory decompression of the optic chiasma and nerves in preparation for adjuvant therapy. However, accelerated growth of the tumor, with renewed visual deficits and mass effect on the hypothalamus and third ventricle, warranted a supplementary resection. A posterior transpetrosal ${ }^{1,2}$ (also called "retrolabyrinthine transtentorial") was performed to obtain a better exposure of the tumor and the surrounding anatomy (floor and walls of the third ventricle, perforating vessels, optic nerves, etc. $)^{3}$. Nuances of technique and surgical pearls related to the posterior transpetrosal are discussed and illustrated in this operative video, including the posterior mobilization of the transverse-sigmoid sinuses junction, preservation of the venous anatomy during the tentorial incision, identification and preservation of the floor of the third ventricle during tumor resection, and a careful multilayer closure. Conclusion Retrochiasmatic craniopharyngiomas are difficult to reach tumors that often require skull base approaches, either endoscopic endonasal or transcranial. The posterior transpetrosal approach is an important part of the surgical armamentarium to safely resect these complex tumors.

The link to the video can be found at: https://youtu.be/2MyGL__v1kl.
\end{abstract}

www.thieme.com/skullbasevideos

www.thieme.com/jnlsbvideos

received

October 20, 2017

accepted

November 29, 2017

published online

January 16, 2018
DOI https://doi.org/

10.1055/s-0037-1620252.

ISSN 2193-6331. (c) 2018 Georg Thieme Verlag KG

Stuttgart · New York
License terms

(c) (i) $\ominus$ (\$) 


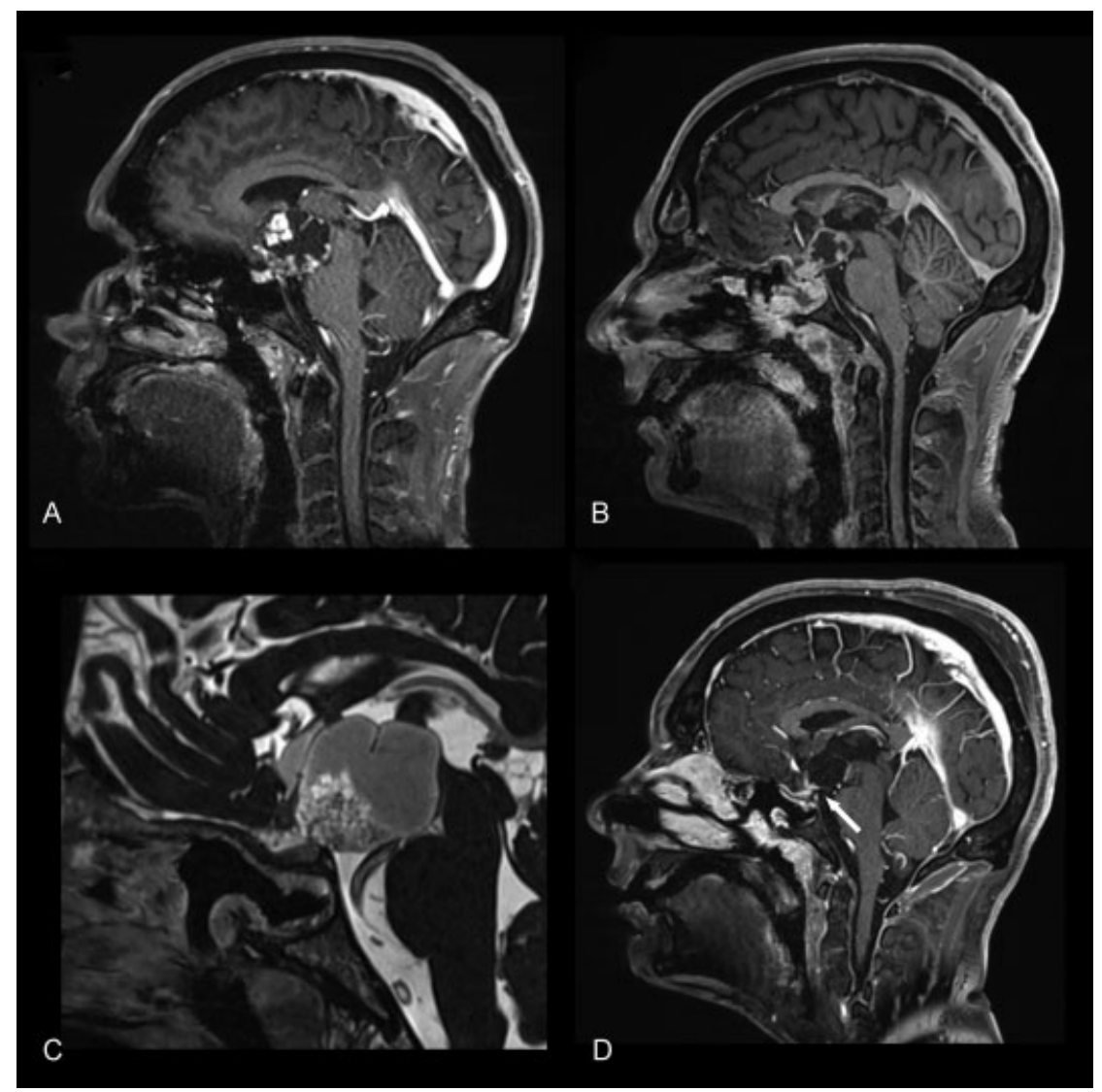

Fig. 1 Preoperative and postoperative imaging. Sagittal gadolinium-enhanced T1 preoperative (A) and (B) postoperative images of the endoscopic transtubercular approach for a large retrochiasmatic craniopharyngioma. Preoperative sagittal CISS image (C) and postoperative sagittal gadolinium-enhanced T1 (D) of the posterior transpetrosal approach.

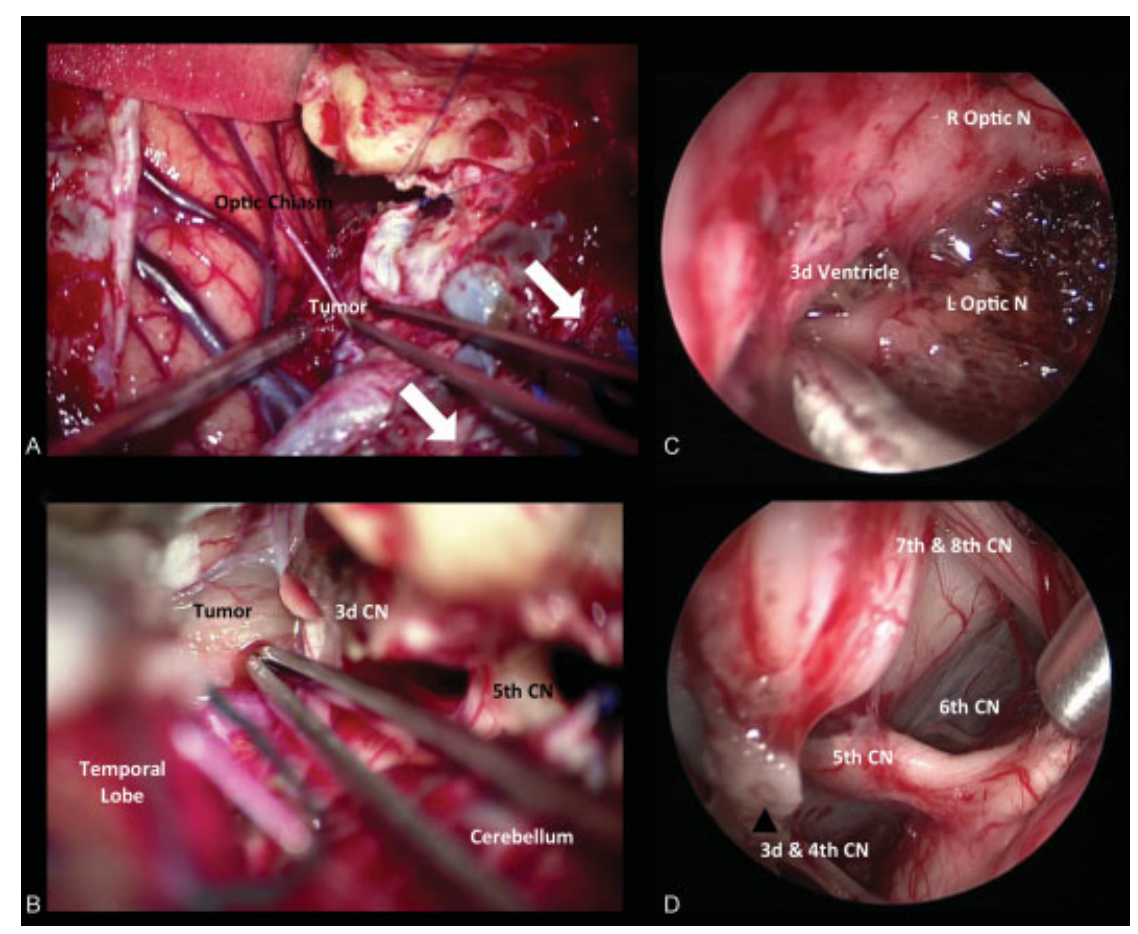

Fig. 2 Intraoperative images. (A) In posterior transpetrosal approach, posterior mobilization of the transverse-sigmoid junction opens up the surgical corridor between the temporal lobe and posterior fossa (white arrows). (B) Initial dissection of the arachnoid of the interpeduncular fossa and exposure of the tumor. Endoscopic assistance allows detailed inspection of the surgical bed (C) and a better appreciation of the surrounding neurovascular anatomy (D). CN, cranial nerve; L optic N, left optic nerve; R optic N, right optic nerve. 
Funding

Local funds.

\section{Conflict of Interest}

None.

\section{References}

1 Al-Mefty O, Ayoubi S, Kadri PAS. The petrosal approach for the total removal of giant retrochiasmatic craniopharyngiomas in children. J Neurosurg 2007;106(2, Suppl)87-92
2 Al-Mefty O, Ayoubi S, Kadri PAS. The petrosal approach for the resection of retrochiasmatic craniopharyngiomas. Neurosurgery 2008;62(05, Suppl 2):ONS331-ONS335, discussion ONS335ONS336

3 Pascual JM, Prieto R, Carrasco R, Barrios L. Displacement of mammillary bodies by craniopharyngiomas involving the third ventricle: surgical-MRI correlation and use in topographical diagnosis. J Neurosurg 2013;119(02):381-405 